\title{
Using information technology
}

to help business students learn about contract law

John S. Edwards and Robert I. Akroyd

Aston Business School, Aston University

This paper describes continuing work in using information technology (IT) to help Business students learn about contract law. The approach adopted uses a model of the contracting process as being one of negotiation, where the decisions made by the parties involve the acceptance or rejection of certain risks. Normal discussion tutorials are therefore replaced by a role-play exercise in which students learn by taking part in simulated negotiations, each interested party being represented by a team of students. IT is being introduced into the learning process, both to provide decision-support for the student teams, and to improve the mechanics of the exercise.

\section{Introduction}

Almost all business students study law. However, business students have a different perspective on law from that of law students. A common problem, therefore, in legal courses for business students is how to provide a sufficiently wide-ranging, practically relevant programme without the sacrifice of intellectual depth. At Aston Business School, one approach adopted has been to supplement lectures with role-play exercises, rather than conventional tutorials.

This paper concentrates on contract law, which also forms a key part of the commercial law module. The principal exercise, Wheeler-dealer, involves the negotiation of contracts, legal relationships and disputes. It has been in use at Aston for several years, originally in paper-based form. Students are divided into two or more teams. Each team is given a particular (real or imaginary) scenario, but is prevented from knowing the full scenario of the opposing team(s). Initially, the teams negotiate a contract or other legal relationship and then, when eventually the deal goes wrong, handle the resulting dispute. The role of the tutor is no longer that of teacher, as it would be in a conventional tutorial. Instead it is to act as referee of the role-play, to advise on the law, and to play the role(s) of any public officials, such as the judge in court proceedings. A more detailed description may be found in Akroyd and Edwards (1994). 
This paper describes the introduction of information technology (IT) into this learning process. Other technology has been incorporated from the beginning, parts of the exercise being video-recorded to enhance the student participants' learning of legal skills.

\section{IT support for role-play exercises in negotiation}

There are two ways in which IT can help students learn from Wheeler-dealer and similar role-play exercises: supporting the student groups in their decision-making (decision support), and supporting the administration of the exercise and the process of negotiation (mechanical support). Our work so far has concentrated on the former.

\section{Decision support}

The field of decision-support systems is only some twenty years old, and many of its problems have not yet been satisfactorily resolved (see, for example, Silver, 1991). Providing decision support which enhances learning is a harder problem still. Fortunately, this task is made feasible because Wheeler-dealer is based on a model of the contracting process, developed by Akroyd (1987). This characterizes the process in terms of negotiation and risk, and thereby provides an appropriate theoretical framework for activities revolving around the practical application of legal principles. A typical Wheeler-dealer roleplay takes place in four phases, two for the Relationship stage and two for the Dispute stage, as shown in Table 1. They are described further in Akroyd and Edwards (1995a).

Table 1: The stages and phases in the negotiating process

\begin{tabular}{|llll|}
\hline Stage & Phase & Title & Activity \\
\hline Preliminary & Introduction & Introduction to the exercise & \\
1. Relationship & la & $\begin{array}{l}\text { Negotiation } \\
\text { Fulfilment }\end{array}$ & $\begin{array}{l}\text { Creation of legal interests and risks } \\
\text { (Non-)fulfilment interests } \\
\text { (Non-)avoidance of risks }\end{array}$ \\
& lb & Litigation & Resolution of disputes \\
2. Dispute & $2 \mathrm{a}$ & Enforcement & Enforcement of awards or judgements \\
& $2 \mathrm{~b}$ & & \\
\hline
\end{tabular}

Initial scenarios are given to student teams at the start of each phase, supplemented as necessary in accordance with a developing situation. Student teams respond by carrying out five functions:

- allocate individual roles;

- research legal and factual information;

- develop a plan to maximize legal interests with a minimum of legal risk; 
- implement the plan in role-play;

- review the outcome of the plan strategically.

As well as giving and receiving evidence of transactions in accordance with the applicable law, play includes the obtaining of any registration, consent, sanction or adjudication from the relevant public authorities (all of which will be role-played by a tutor) in the correct manner. This necessitates accurate prior identification of such bodies and careful appraisal of the process involved.

One system (Sales Contractor) to provide decision support for the players has been developed, and another (Contract Negotiator) is in the process of construction. Sales Contractor is written in the expert system shell Xi Plus, and advises on drawing up a contract for the sale of goods (see Akroyd and Edwards, 1995b). Its function is that of a decision-support system rather than that of the classic expert system, since the final choice is always left with the user. This is particularly satisfactory for learning purposes. In Wheeler-dealer, it is most useful in helping to draft documentary evidence of sales contract terms and conditions of trade. The detailed wording of clauses or advice was based on Akroyd (1984).

One screen from Sales Contractor, regarding provisions for checking the goods, is shown in Figure 1.

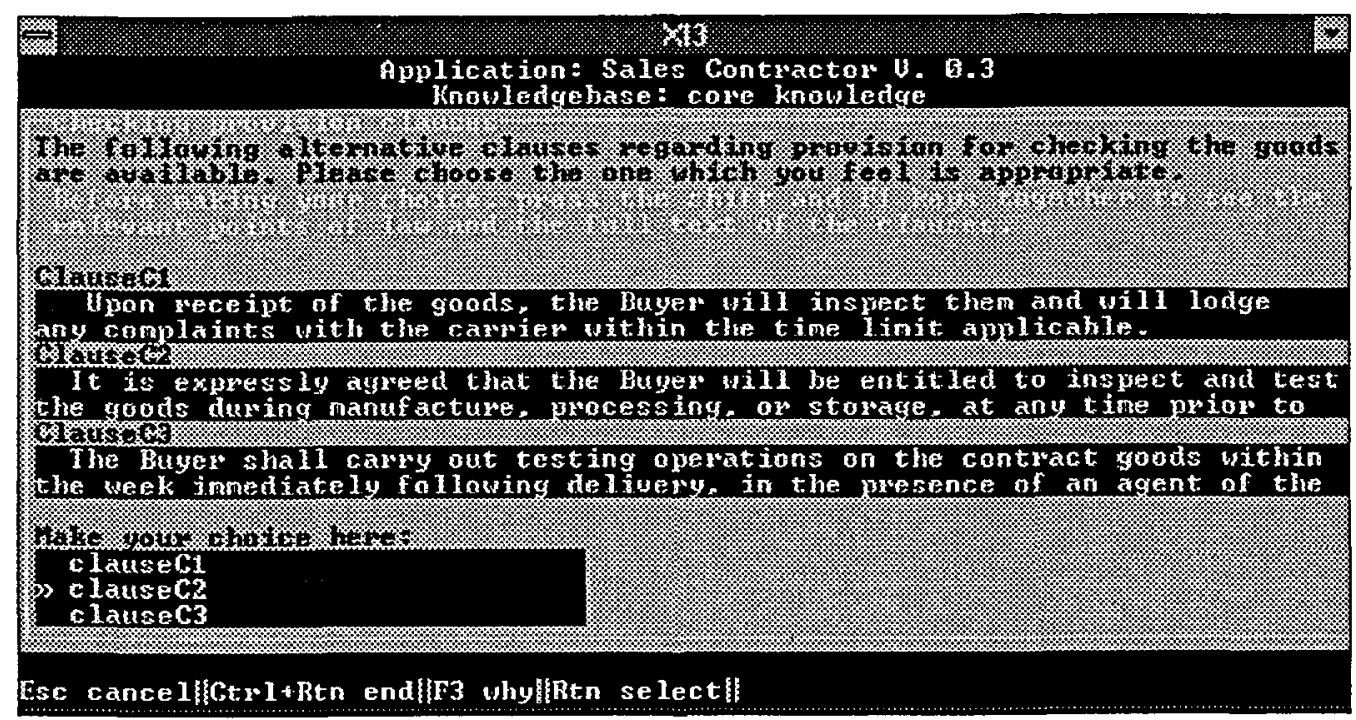

Figure 1: A Sales Contractor screen regarding provisions for checking the goods

Contract Negotiator is intended to provide more comprehensive support for the entire 
negotiation, and is at present under development using the hypermedia package Guide. It consists of a series of 36 questions, each relating to a set of legal issues, running through phases $1 \mathrm{a}, 1 \mathrm{~b}, 2 \mathrm{a}$ and $2 \mathrm{~b}$ (see Table 1). This main structure is supported by:

- a Research Menu, allowing access to a digest of legal advice, the online database LEXIS, and databases of contract and procedural forms;

- a Risk Advisor, in the event of the user wishing to proceed without sufficient proof of relevant legal principle or fact;

- an Action Pad, allowing access to Sales Contractor, a word-processing package, electronic mail, and in principle also telephone or fax.

Contract Negotiator is at present in prototype form. An example of a question from phase 1a is shown in Figure 2.

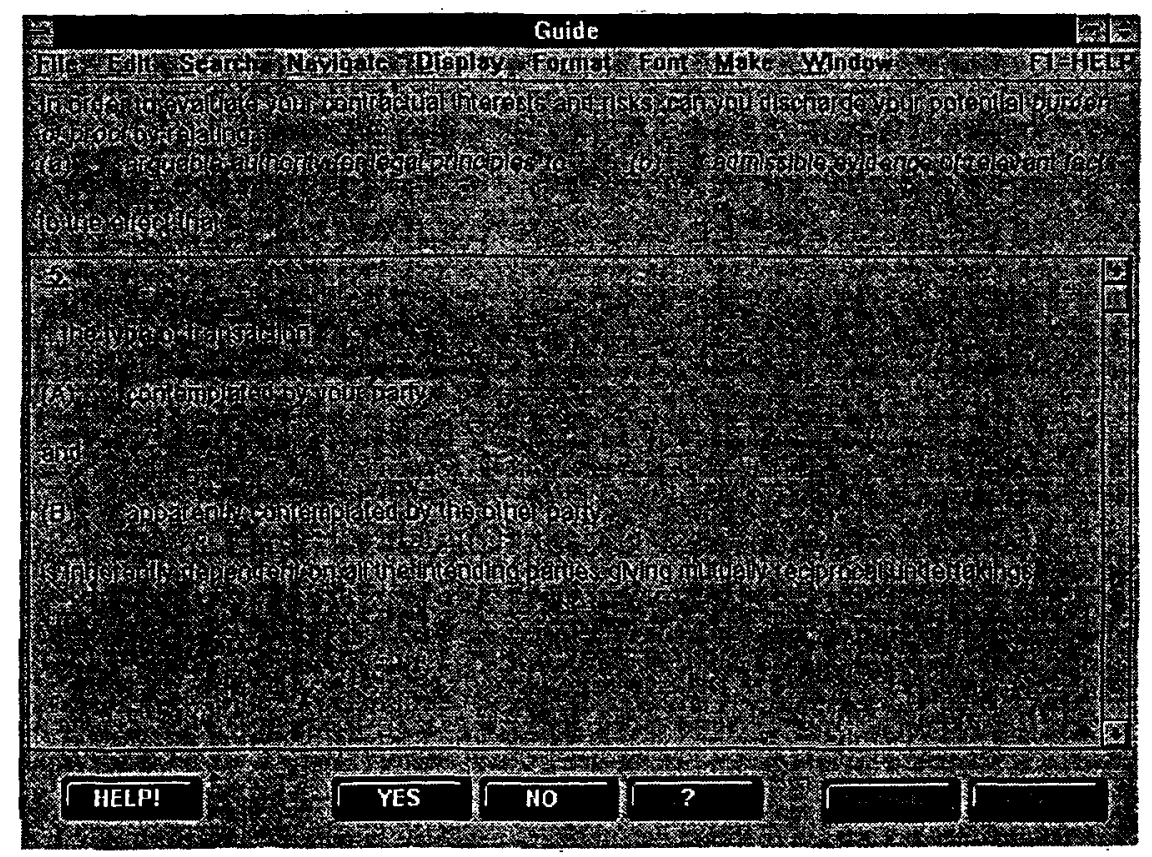

Figure 2: An example of a question from Contract Negotiator

For each question, the only possible answers are Don't know, No or Yes. Figure 3 shows the relationship between these answers and the parts of Contract Negotiator, and how these relate to the functions in the negotiating process.

The current (third) prototype of Contract Negotiator is the first networked version, adding access to LEXIS and electronic mail to the capabilities of the second prototype. 


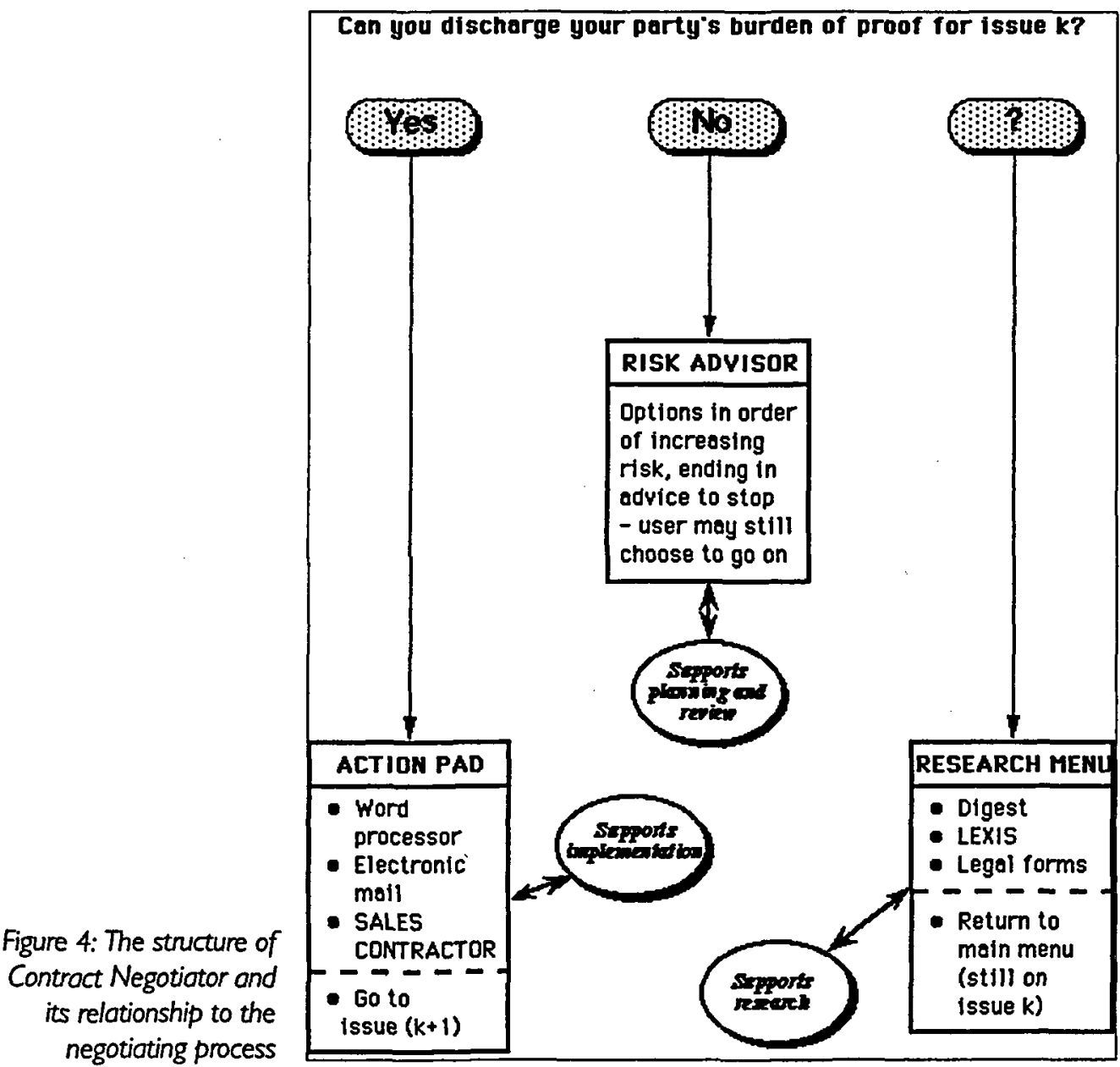

There is no significant software problem in including links to further applications packages, or to communications media such as telephone and fax in the Action Pad - only the hardware problem of ensuring that suitable connections, such as fax modems, exist.

\section{Mechanical support}

The use of networked systems to enable file transfer and electronic mail between participants has been technologically feasible for some years, and has now reached the stage where the use of such facilities is sufficiently familiar as to impose no extra burden on business students. However, two related issues remain. The first is that replacing physical paper delivery of documents and face-to-face contact by electronic means may reduce the opportunity for feedback between tutor and student. We believe that an application such as Fujitsu's DTC (DeskTop Conferencing) software, enabling tutor and student to work on the same display while in different locations, may avoid this. We hope 
student to work on the same display while in different locations, may avoid this. We hope to experiment with this in the coming year. The second problem is less easily dealt with. Under English law, the legal status of a document stored only as a file on a computer is not the same as that of a printed one. It would thus be both unwise and unrealistic to replace paper with electronic 'documents' in Wheeler-dealer to any greater extent than is already done in the real world (for example, the use of a word processor to produce standard contracts).

\section{Evaluation}

Trials of Sales Contractor have been carried out with commercial law students, who used the system to produce contracts as part of their coursework. This meant that a fully controlled experiment was not possible; it would not have been fair, in academic terms, to have a control group. Comparisons are therefore at a broad level, and on an indirect basis, against students undertaking the module in previous years.

Sales Contractor has proved easy to use and robust. Specific advantages are:

- The production of a contract is very much quicker, taking about five minutes for a user moderately familiar with the choices offered. This compares with a typical time period previously of between one and three hours, often spread over more than one day.

- The contracts produced are, in the tutors' judgement, inherently better than those produced previously, even with access to standard practitioners' works such as the Encyclopaedia of Forms and Precedents (1985). This is because the system facilitates the choice of suitable, well drafted provisions, and militates against total omission of provisions, previously a common fault.

- The students find the on-screen legal advice more digestible than the textbook format, for two reasons. The first is that it comes in relatively small and manageable chunks, and the second is the use of colour to distinguish references to legal authority and cases from the text of the advice.

- The system can be used to produce alternative contract versions for comparison.

A number of limitations and weaknesses have also become apparent:

- The present system has no facility for the user to modify the provisions. Such a facility would have to allow change while preventing the introduction of errors, which is difficult to achieve without compromising the normative effect of the system, since the users, by definition, have little legal expertise.

- It is still possible for a user to produce a wilfully or recklessly inappropriate contract.

- As a learning aid, the full range of potential clauses on each point has been curtailed.

- The suggested clauses are often too long to fit into the fields available. This is because we have been using $\mathrm{Xi}$ Plus running under DOS. An implementation based on Windows or another graphical user-interface which allowed more flexible scrolling and 
resizing would minimize this problem. We intend to try the version of Xi Plus for Windows which has recently become available.

\section{Conclusion}

Sales Contractor is designed for a specific task, namely producing contracts for the sale of goods, and has already proved useful to business students studying law. Contract Negotiator will provide more general support for the negotiation of contracts, legal relationships and disputes. More than just a stand-alone system, it is also a structure linking several other applications, including Sales Contractor (it is due to be tested with students during the academic year 1994/95). The suitability of these two systems for student learning, although they are decision-support systems, arises because they are structured around the relevant legal principles.

\section{References}

Akroyd, R.I. (1984), A Guide to Contracting for the Sale of Goods, London, Routledge and Kegan Paul.

Akroyd, R.I. (1987), A Guide to Contracting: Negotiation and the Law, London, Routledge and Kegan Paul.

Akroyd, R.I. \& Edwards, J.S. (1994), 'Wheeler-dealer: a role-play concept for learning about legal negotiation', International Journal of Independent Studies (submitted).

Akroyd, R.I. \& Edwards, J.S. (1995a), 'Computer-supported contract negotiation: Contract Negotiator - an experimental prototype', International Journal of Applied Expert Systems (submitted.

Akroyd, R.I. \& Edwards, J.S. (1995b) 'Computer-supported contract drafting: Sales Contractor - an experimental prototype', International Journal of Applied Expert Systems, 3 (in press).

Silver, M.S. (1991), Systems that Support Decision Makers: Description and Analysis, Chichester, Wiley.

Walton, R. (ed.) (1985 onwards), The Encyclopaedia of Forms and Precedents (5th edition), in 44 volumes, London, Butterworths. 